Supplement of Hydrol. Earth Syst. Sci., 20, 175-191, 2016

http://www.hydrol-earth-syst-sci.net/20/175/2016/

doi:10.5194/hess-20-175-2016-supplement

(C) Author(s) 2016. CC Attribution 3.0 License.

(c) (i)

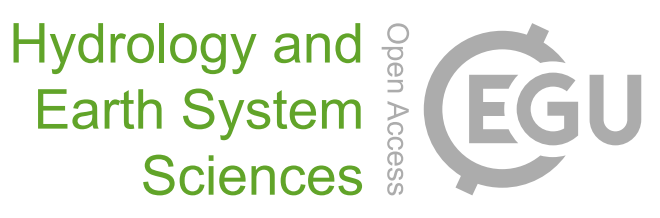

Supplement of

\title{
Assessing various drought indicators in representing summer drought in boreal forests in Finland
}

\author{
Y. Gao et al. \\ Correspondence to: Y. Gao (yao.gao@fmi.fi)
}

The copyright of individual parts of the supplement might differ from the CC-BY 3.0 licence. 
(a) $\mathrm{SPI}_{\text {forcing }}$ VS. $S P \mathrm{I}_{\text {obs }}$

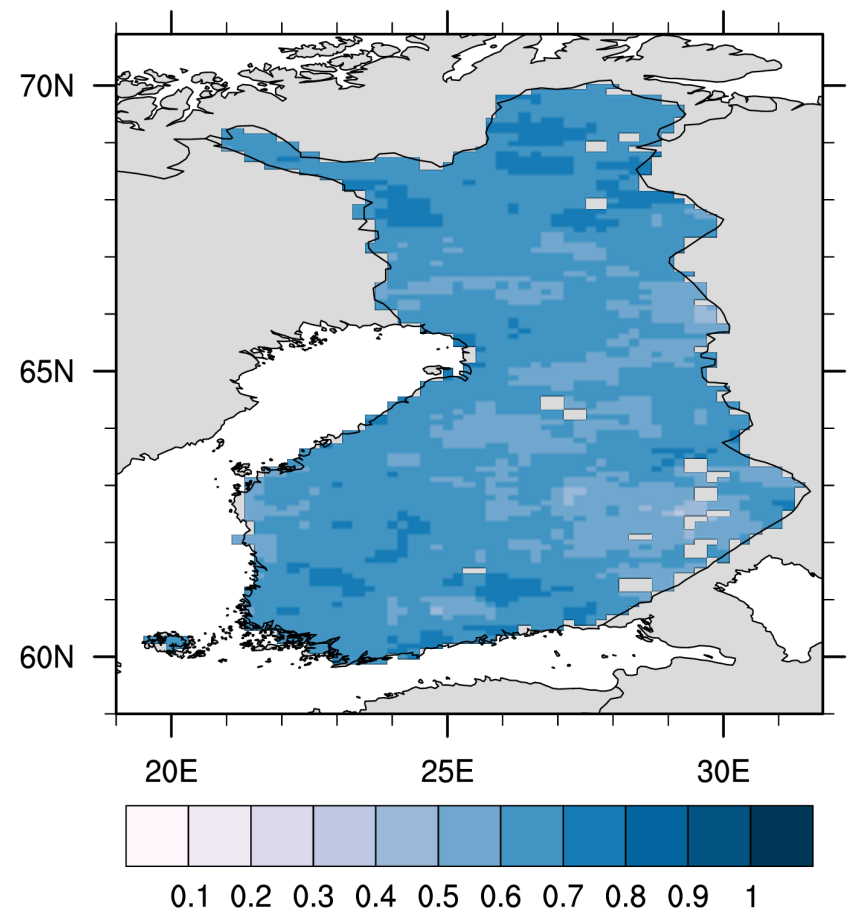

(b) $\mathrm{SPEI}_{\text {forcing }}$ Vs. $\mathrm{SPEI}_{\mathrm{obs}}$

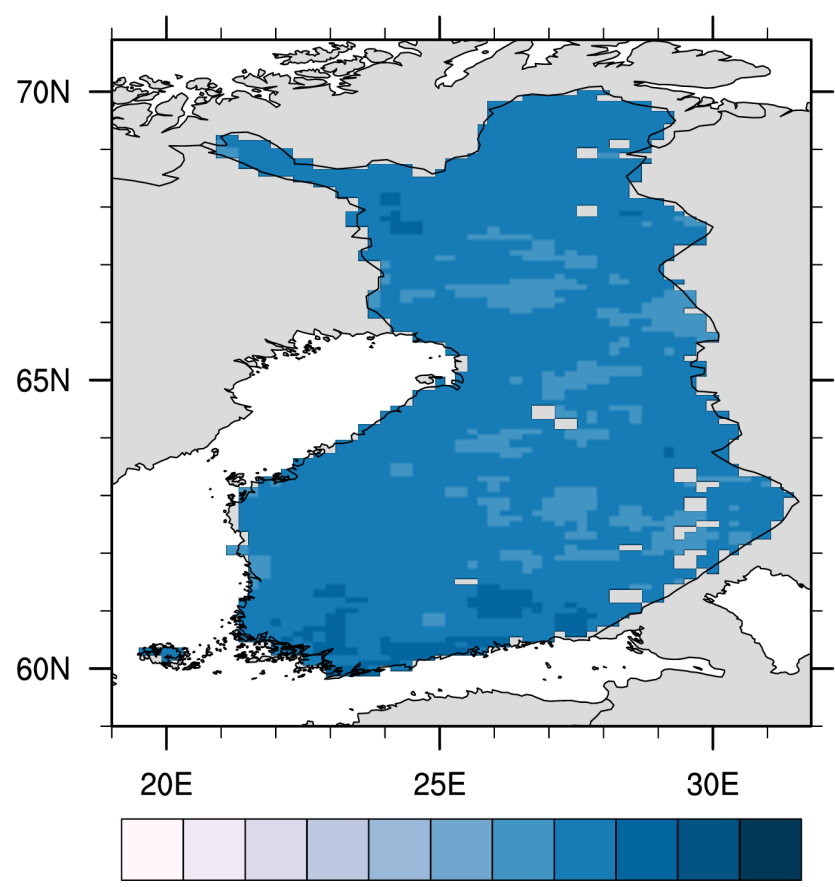

$\begin{array}{llllllllll}0.1 & 0.2 & 0.3 & 0.4 & 0.5 & 0.6 & 0.7 & 0.8 & 0.9 & 1\end{array}$ 
(c) $\mathrm{SPI}_{\text {forcing }}$ VS. SMI

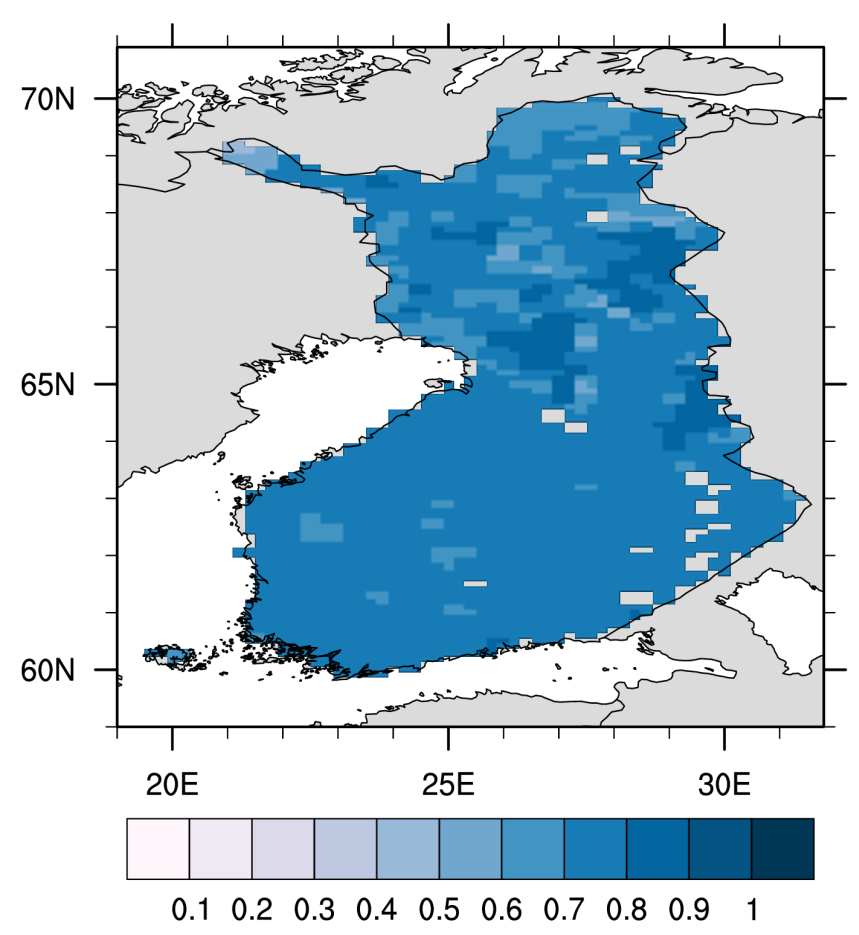

(d) $\mathrm{SPI}_{\text {forcing }}$ vs. SMA

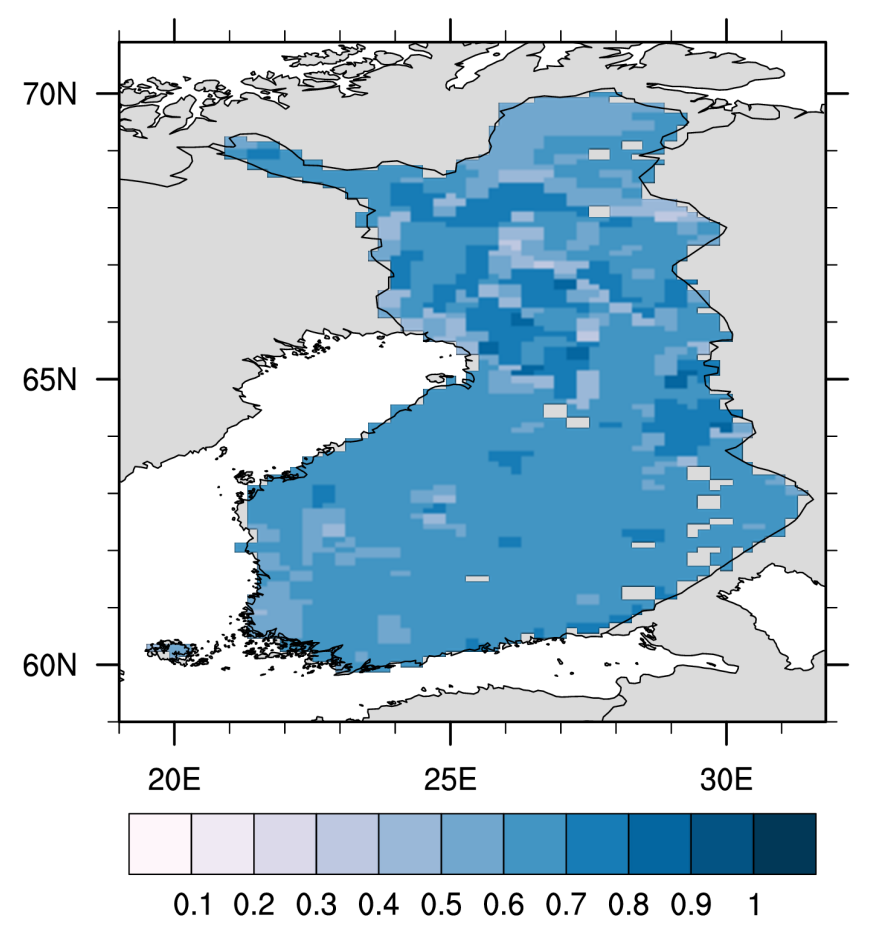


(e) $\mathrm{SPEI}_{\text {forcing VS. SMI }}$

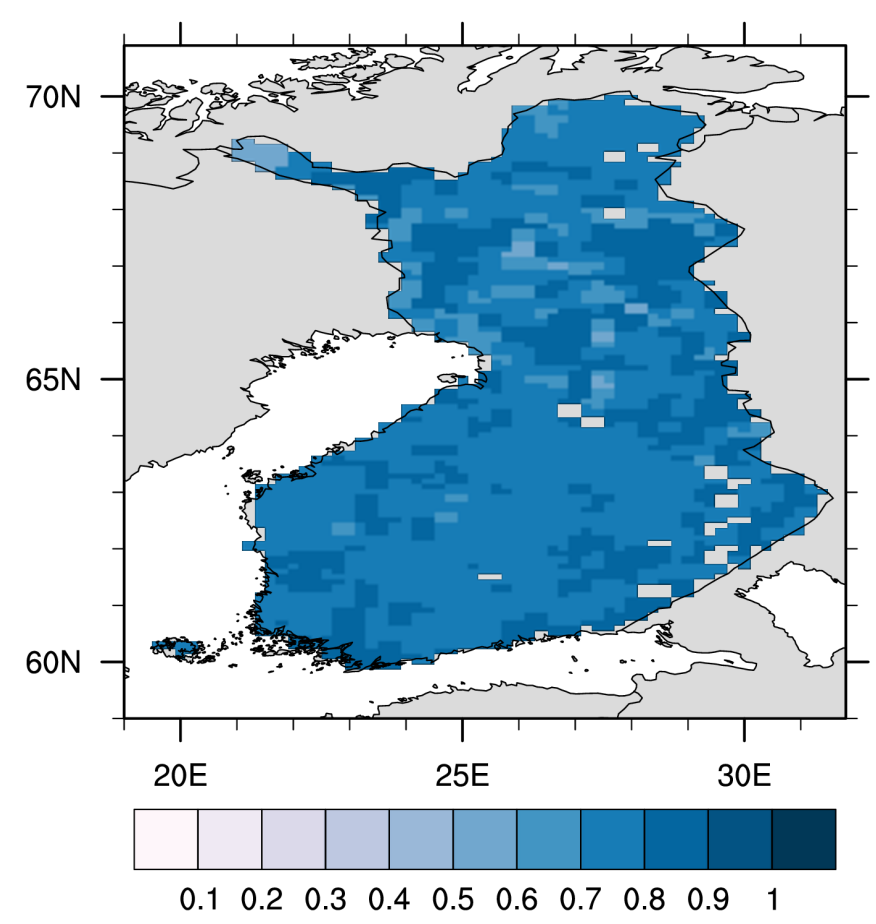

(f) $\mathrm{SPEI}_{\text {forcing }}$ vs. SMA

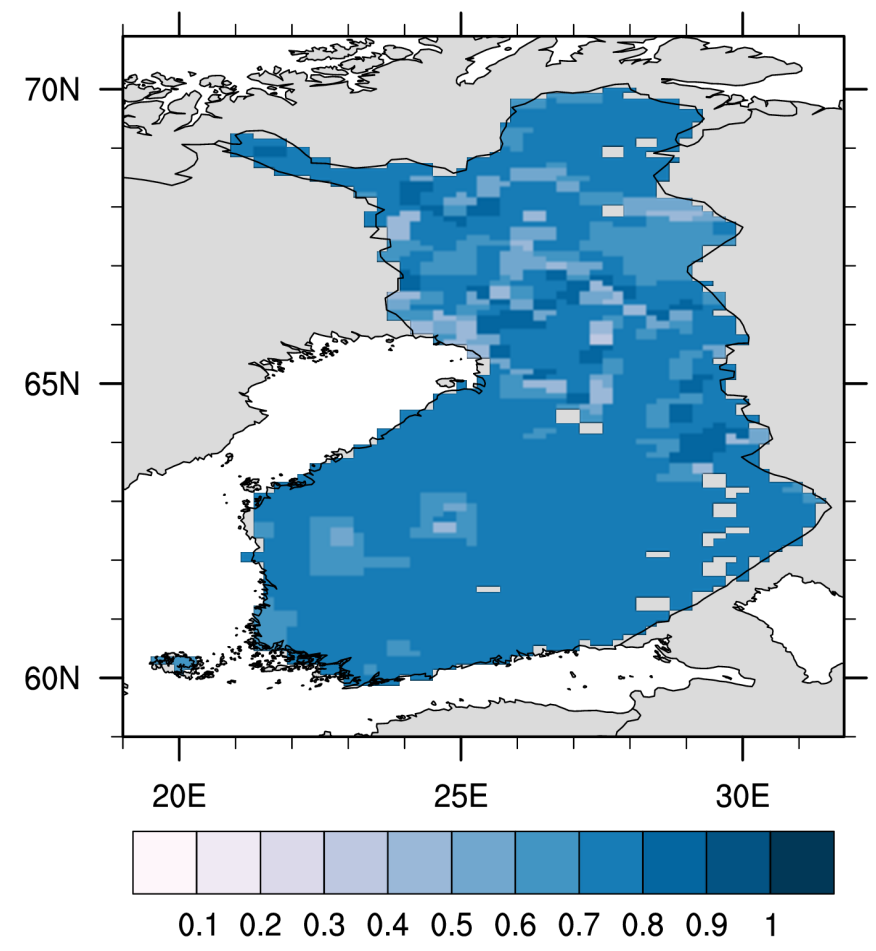


(g) SMI vs. SMA

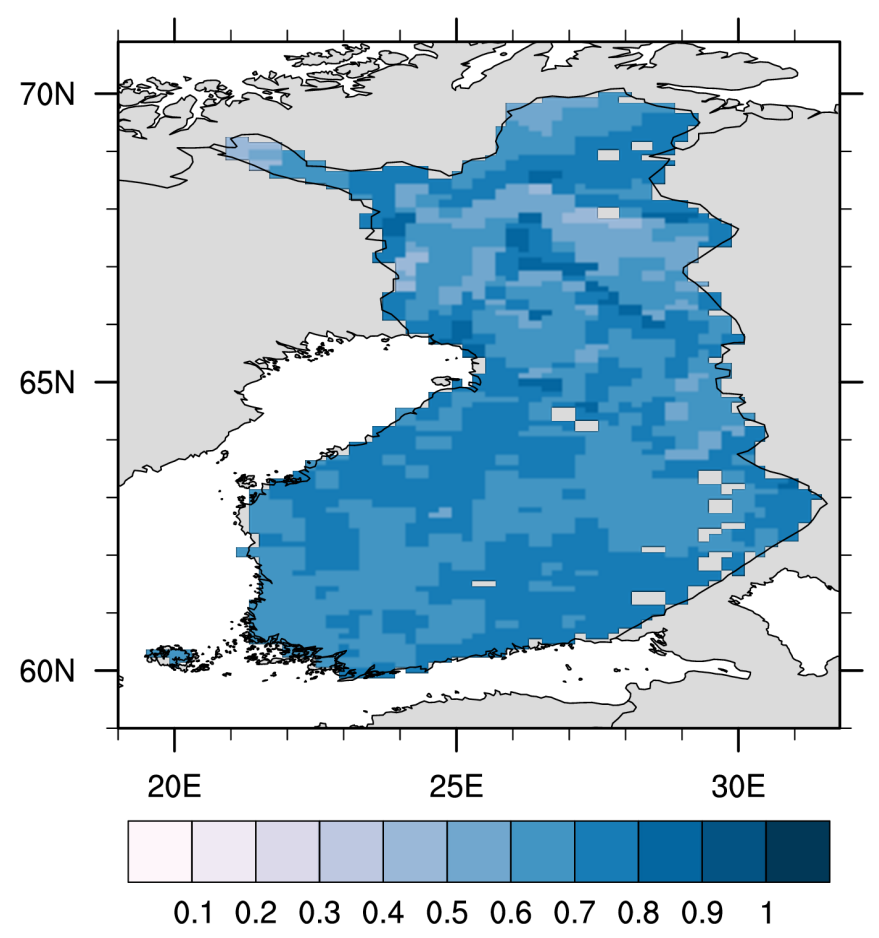

Figure S1. The time correlation coefficients between the SPIs and SPEIs derived from the JSBACH forcing data and the observational dataset over the summer months of the 30 year study period ( (a) $\mathrm{SPI}_{\text {forcing }}$ VS. SPI $\mathrm{Sbs}_{\mathrm{ob}}$ (b) $\mathrm{SPEI}_{\text {forcing }}$ Vs. $\mathrm{SPEI}_{\mathrm{obs}}$ ), and the time correlations between SPI, SPEI calculated with the JSBACH forcing data and SMI, SMA calculated with the JSBACH simulated soil moisture

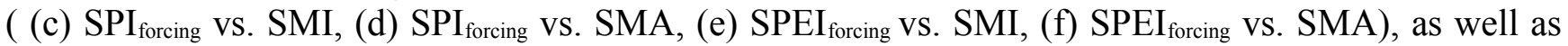
the time correlation between SMI and SMA calculated with the JSBACH simulated soil moisture in the study period ( (g) SMI vs. SMA). Those correlation coefficients are statistically significant $(\mathrm{P}<0.01)$. The uncovered grid boxes (grey cells) in Finland are inland lakes. 